\title{
Article \\ Influence of Bifilm Defects Generated during Mould Filling on the Tensile Properties of Al-Si-Mg Cast Alloys
}

\author{
Mahmoud Ahmed El-Sayed ${ }^{1}\left(\mathbb{D}\right.$, Khamis Essa ${ }^{2}\left(\mathbb{D}\right.$ and Hany Hassanin ${ }^{3, *(D)}$ \\ 1 Department of Industrial and Management Engineering, Arab Academy for Science and Technology and \\ Maritime Transport, P.O. Box 1029, Abu Qir, Alexandria 21599, Egypt; dr.mahmoudelsayed12@gmail.com \\ 2 School of Engineering, University of Birmingham, Birmingham B15 2TT, UK; k.e.a.essa@bham.ac.uk \\ 3 School of Engineering, Technology and Design, Canterbury Christ Church University, \\ Canterbury CT1 1QU, UK \\ * Correspondence: hany.hassanin@canterbury.ac.uk
}

Citation: El-Sayed, M.A.; Essa, K.; Hassanin, H. Influence of Bifilm Defects Generated during Mould Filling on the Tensile Properties of Al-Si-Mg Cast Alloys. Metals 2022, 12, 160. https://doi.org/10.3390/ met12010160

Academic Editors: Wenming Jiang and Noé Cheung

Received: 18 November 2021

Accepted: 5 January 2022

Published: 16 January 2022

Publisher's Note: MDPI stays neutral with regard to jurisdictional claims in published maps and institutional affiliations.

Copyright: (C) 2022 by the authors. Licensee MDPI, Basel, Switzerland. This article is an open access article distributed under the terms and conditions of the Creative Commons Attribution (CC BY) license (https:// creativecommons.org/licenses/by/ $4.0 /)$.

\begin{abstract}
Entrapped double oxide film defects are known to be the most detrimental defects during the casting of aluminium alloys. In addition, hydrogen dissolved in the aluminium melt was suggested to pass into the defects to expand them and cause hydrogen porosity. In this work, the effect of two important casting parameters (the filtration and hydrogen content) on the properties of Al-7 Si-0.3 Mg alloy castings was studied using a full factorial design of experiments approach. Casting properties such as the Weibull modulus and position parameter of the elongation and the tensile strength were considered as response parameters. The results suggested that adopting 10 PPI filters in the gating system resulted in a considerable boost of the Weibull moduli of the tensile strength and elongation due to the enhanced mould filling conditions that minimised the possibility of oxide film entrainment. In addition, the results showed that reducing the hydrogen content in the castings samples from 0.257 to $0.132 \mathrm{~cm}^{3} / 100 \mathrm{~g} \mathrm{Al}$ was associated with a noticeable decrease in the size of bifilm defects with a corresponding improvement in the mechanical properties. Such significant effect of the process parameters studied on the casting properties suggests that the more careful and quiescent mould filling practice and the lower the hydrogen level of the casting, the higher the quality and reliability of the castings produced.
\end{abstract}

Keywords: bifilm; Al-7 Si-0.3 Mg alloy; hydrogen; filtration; Weibull modulus

\section{Introduction}

Aluminium alloys are the most used materials in the automotive industry due to their excellent properties such as strength, durability, safety and low density, resulting in reduced emissions and an increase in fuel efficiency of the produced vehicles. In addition, aluminium is a fully recyclable material without losing recycled quality. Therefore, there is an accelerated demand for innovations and developments for aluminium alloys, particularly regarding improving the mechanical properties of the cast components [1-6].

Cast aluminium alloys are shown to have low gas absorption, with the exception of hydrogen [7-10]. Oxide film defects (bifilms) are typically created due to surface disturbance of the Al melt during pouring and/or transfer processes. This causes the oxidised surface to be folded upon itself entrapping an air layer within it and then be entrained in the bulk liquid Al [11-14]. Entrainment of bifilm defects is one of the most significant issues in aluminium castings, as they are claimed to deteriorate the tensile and fatigue properties. They are also promoting the creation of other casting defects such as pores and iron intermetallics [15-17].

Research studies showed that the bifilm defects occurrence during the pouring of the melt could be explained through the critical ingate velocity concept. As the melt enters the mould cavity with a speed more than a critical value (about $0.5 \mathrm{~m} / \mathrm{s}$ for most aluminium alloys), the flow front becomes unstable and allows the creation of surface 
oxide foldable layers [18-22]. Literature has also confirmed that it is challenging to produce reliable casting and avoid oxide film entrainment using top-pouring methods. Therefore, bottom-pouring gating techniques are preferred because they avoid instability of melt flow behaviour during mould filling by controlling the ingate-velocity requirements for sound castings [23-26].

During solidification of the cast, the solubility of the hydrogen in Al melt considerably drops causing the former to be rejected by the growing dendrites. Concurrently, entrained bifilms, initially being compacted due to bulk turbulence, start to unfurl due to the negative pressure ascending from the shrinkage of the cast. This behaviour causes hydrogen to diffuse into the developed bifilm and inflate them into pores [27]. The results recently supported these findings by El-Sayed, Chen and Griffiths that demonstrated a harmful influence of hydrogen on the mechanical properties of an Al casting [28-31].

Design of experiments (DoE) is a systematic approach used to plan, conduct, and analyse tests to study the effect of different parameters of a given process on the response(s) of that process through performing the minimum number of experiments [32-35]. A twolevel full factorial design is one of the most widely used experimental designs in which each of the process parameters is set at two levels. These levels are called 'high' and 'low', 'Good' and 'Bad' or ' +1 ' and ' -1 '. A factorial design denoted $2^{\mathrm{k}}$ design is a full factorial design of $\mathrm{k}$ parameters - each has two levels, and the design will involve $2^{\mathrm{k}}$ runs [36].

Previous investigations about casting of light alloys had looked at the effect of different casting parameters on the mechanical properties. However, not many attempts in the literature have been made to identify which of these parameters had a statistically significant effect on the tensile properties of Al-Si-Mg cast alloys. The current research was carried out to cover the research gap and utilizes statistical techniques by means of Full Factorial Design of Experiments (DoE) and Analysis of Variance (ANOVA) to identify the significance of casting process parameters and study their effect on the UTS and \% elongation of the castings produced. In addition, the application of DoE not only allowed to statistically assess the significance of the studied parameters, it also provided a sort of quantification of the weight of each parameter in impacting the studied process outputs through the calculation of the standardised effect of each factor. Finally, the use of DoE allowed also to assess the interaction effect between the studied parameters, which is very difficult, if not impossible, to determine otherwise.

In this paper, the effect of the hydrogen content of aluminium casting and the use of filters on the amount and size of bifilm defects, and by implication on the properties of Al-7 Si-0.3 Mg alloy castings was studied. A two-factor DoE was used for the modelling and the analysis of the casting process. The aim of such study is to provide a better understanding of the factors dominating the quality and reproducibility of light metal cast alloys.

\section{Experiment}

The two-parameter Weibull distribution is an empirical distribution [37] introduced by Weibull in 1951, and the distribution function is expressed as

$$
\mathrm{P}=1-\exp \left\{-\left[\mathrm{x} / \mathrm{x}_{0}\right]^{\mathrm{m}}\right\}
$$

where:

$\mathrm{P}=$ the cumulative fraction of failures in the mechanical property, e.g., a tensile test;

$\mathrm{x}=$ variable being measured, e.g., tensile strength;

$\mathrm{x}_{0}=$ position parameter or characteristic value at which $63 \%$ of the samples failed;

$\mathrm{m}=$ Weibull modulus.

Taking the logarithm of Equation (1) twice yields a linear equation:

$$
\ln [-\ln (1-P)]=m \ln (x)-m \ln \left(x_{0}\right)
$$


with a slope of " $\mathrm{m}$ " and an intercept of " $-\mathrm{m} \ln \left(\mathrm{x}_{0}\right)$ ". When " $\ln [-\ln (1-\mathrm{P})]$ " is plotted versus " $\ln (\mathrm{x})^{\prime}$ ", Weibull probability plot is obtained and therefore the values of " $\mathrm{m}$ " and " $\mathrm{x}_{0}$ " could be determined [20].

Literature suggests that Weibull distribution could better explain the failure of materials under a mechanical loading than a normal distribution [37,38]. A greater Weibull modulus and position parameters mean that the samples have fewer defects, which indicate higher and more reproducible properties. This study employed a two-parameter Weibull distribution to quantify the variability of the ultimate tensile strength and the \% elongation of Al-Si-Mg cast alloys.

In this study, castings from $\mathrm{Al}-7 \mathrm{wt} \% \mathrm{Si}-0.3 \mathrm{wt} . \% \mathrm{Mg}$ alloy were produced using gravity casting technique. Hydrogen contents and filtration were the two factors of the sand casting process that were considered for the experimentation. In addition, four process outputs or study responses were considered in this study. They were the cast Weibull modulus and position parameter of the UTS (denoted mUTS $_{\text {Und }} \mathrm{x}_{0 \text { )UTS, }}$, respectively), and the Weibull modulus and position parameter of the elongation (denoted $\mathrm{m}_{\mathrm{ELONG}}$ and

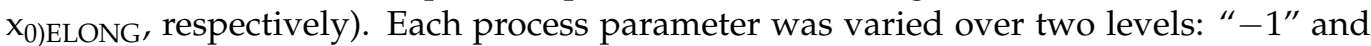
" +1 ". The experiment, therefore, contained four combinations of hydrogen contents and filtration. The design matrix of the experimental work is shown in Table 1.

Table 1. Experimental plan.

\begin{tabular}{cccccc}
\hline & \multicolumn{5}{c}{ Experiment } \\
\hline Factor & $\begin{array}{c}\text { Coded } \\
\text { Symbol }\end{array}$ & $\mathbf{1}$ & $\mathbf{2}$ & 3 & 4 \\
\hline $\begin{array}{c}\text { Hydrogen content of } \\
\text { the casting }\end{array}$ & $\mathrm{A}$ & -1 & +1 & -1 & +1 \\
\hline Level & - & (High) & (Low) & (High) & (Low) \\
\hline Filtration & B & -1 & -1 & +1 & +1 \\
\hline Level & - & (Unfiltered) & (Unfiltered) & (Filtered) & (Filtered) \\
\hline
\end{tabular}

A two-level full factorial study was applied to explore the effects of hydrogen contents and filtration and their interaction using Design-Expert Software Version 7.0.0 (Stat-Ease Inc., Minneapolis, MN, USA). Figure 1a shows a sketch of the pattern geometry used to produce the resin-bonded sand moulds. The mould consists of ten tensile test bars of a length of $100 \mathrm{~mm}$ and a diameter of $11 \mathrm{~mm}$. The runner used in this mould had a thickness of $25 \mathrm{~mm}$. Two moulds were cast to produce 20 tensile test bars for each of the four experiments listed in Table 1 . In each experiment, about $6 \mathrm{~kg}$ of Al-7 Si-0.3 Mg alloy were melted in an induction furnace (Inductotherm, Droitwich, United Kingdom ). The melt was kept at $800{ }^{\circ} \mathrm{C}$ under a partial vacuum atmosphere of 0.2 bar for $2 \mathrm{~h}$ before pouring to allow the expansion of the charge oxide films and consequent floating to the melt surface, which helps to remove them as suggested in the literature [29]. The melt was then poured into the moulds in such a way to promote the creation of fresh bifilms.

In order to evaluate the effect of the hydrogen content in the casting samples, the experiments were grouped into two categories - the first category includes samples with high hydrogen content (Experiments 1,3), and the second category includes samples low hydrogen content (Experiments 2, 4). For Experiments 1 and 3 the molten aluminium was poured into the moulds that had been prepared one day before the experiment. As for Experiments 2 and 4, and in order to ensure obtaining castings with low hydrogen content, degassing was carried out using AISCAN equipment (ABB Measurement \& Analytics, Pennsylvania, USA) for $30 \mathrm{~min}$ before pouring. In addition, and to eliminate hydrogen picking up from the mould walls, the moulds were kept under a reduced pressure of 0.5 bar for 14 days before the experiment in order to allow the resin solvent to evaporate completely from the sand moulds [28]. For Experiments 3 and 4, two ceramic filters (Fesoco, Birmingham, United Kingdom) of 10 pores per linear inch (PPI) and dimensions 
of $50 \times 50 \times 20 \mathrm{~mm}$, were placed in the filter prints at the locations shown in Figure 1 a. This would allow better control of the melt flow inside the mould, aiming to reduce the possibility of oxide film entrainment. After solidification of the cast, samples were cut from the runner bar, and hydrogen measurement was analysed using LECO $^{\text {тм }}$ hydrogen analyser (LECO, St. Joseph, MI, USA) for solid-state hydrogen measurement of the castings from different experiments.

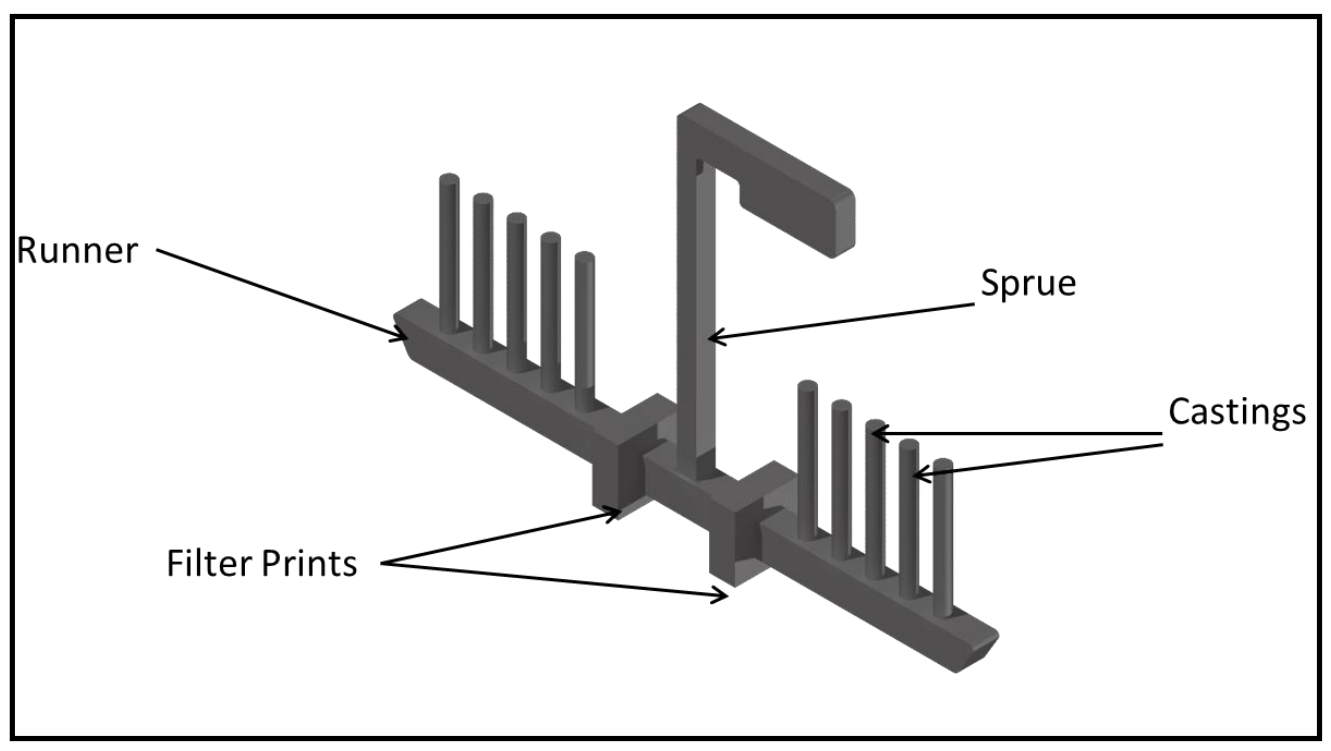

(a)

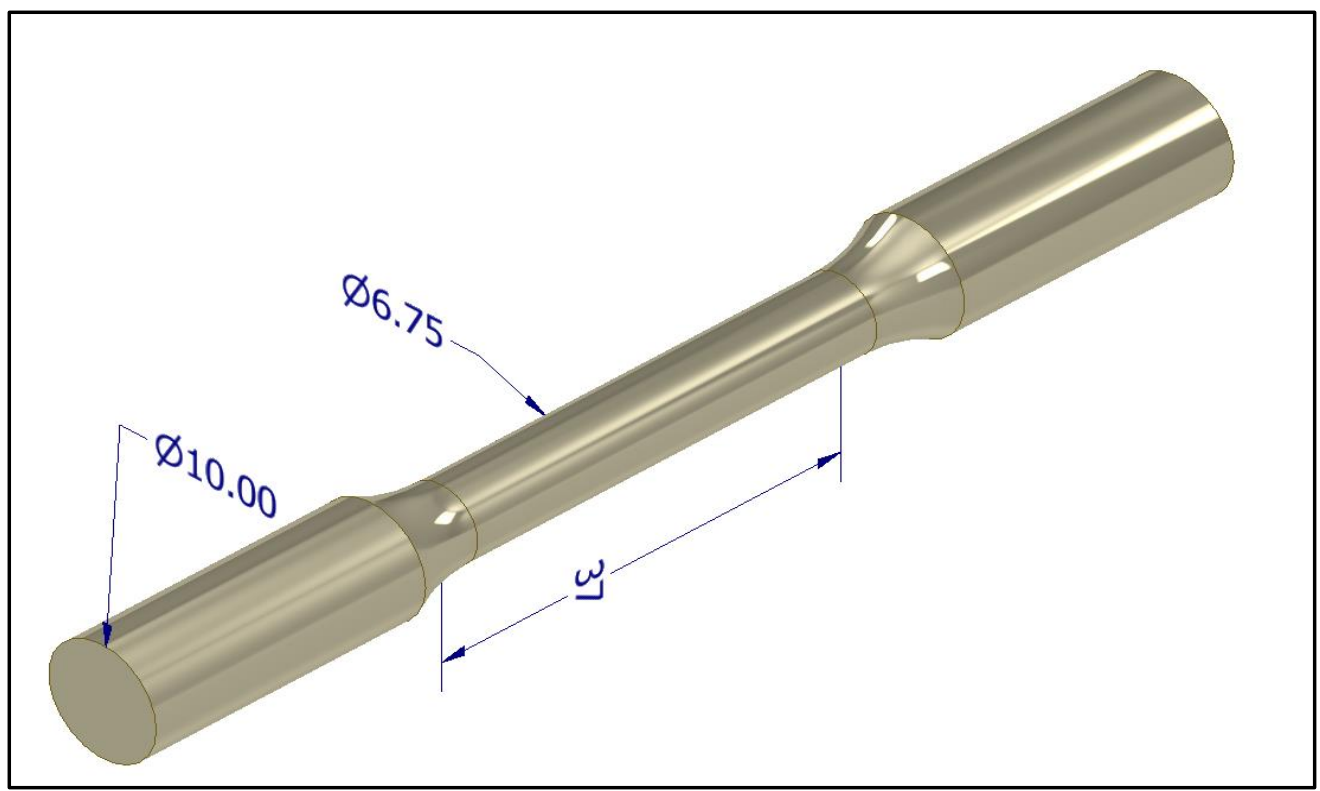

(b)

Figure 1. A schematic diagram of (a) the pattern used to create the mould, (b) a tensile test sample (dimensions in $\mathrm{mm}$ ).

Tensile test samples were prepared by machining the solidified castings using a turning machine. Figure $1 \mathrm{~b}$ shows a schematic of the tensile test samples. Testing was performed with a WDW-100E universal testing machine (Time Group Inc., Beijing, China) with a strain rate of $1 \mathrm{~mm} \mathrm{~min}^{-1}$. The ultimate tensile strength (UTS) and \% elongation results were assessed using a two-parameter Weibull distribution to evaluate the effect of the 
casting parameters on the scatter of the casting tensile properties. Finally, the broken tensile test samples were examined using a Philips XL-30 scanning electron microscope (SEM) (SEMTech Solutions, Inc., North Billerica, MA, USA ) equipped with an energy dispersive X-ray analyser (EDS) for the evidence of bifilm. For each of Experiments 1 and 4, three specimens were selected for investigation that showed the lowest UTS, as they were expected to include more oxide film defects.

\section{Results and Discussion}

As discussed, aluminium alloy melt was held under vacuum to eliminate the effect of previously introduced oxides in the raw material and ensure that the castings' variability is only due to the changed casting process parameters $[27,36]$. These process parameters or casting conditions are the amount of hydrogen in the solidified casting and the filtration.

Table 2 lists the casting conditions of the experiments performed and the corresponding Weibull analysis results for different properties.

Table 2. Position parameter and Weibull modulus of cast specimens produced under different conditions.

\begin{tabular}{ccccccc}
\hline \multirow{2}{*}{$\begin{array}{c}\text { Exp. } \\
\text { No. }\end{array}$} & $\begin{array}{c}\text { Hydrogen Level } \\
\left(\mathbf{c m}^{\mathbf{3}} \mathbf{1 0 0} \mathbf{g} \text { Al) }\right.\end{array}$ & Filtration & $\begin{array}{c}\text { Position } \\
\text { Parameter }\end{array}$ & $\begin{array}{c}\text { Weibull } \\
\text { Modulus }\end{array}$ & $\begin{array}{c}\text { Position } \\
\text { Parameter }\end{array}$ & $\begin{array}{c}\text { Weibull } \\
\text { Modulus }\end{array}$ \\
\cline { 3 - 6 } & 0.257 & Unfiltered & 81 & 4.15 & 4.08 & 2.17 \\
1 & 0.132 & Unfiltered & 106 & 8.95 & 4.92 & 6.14 \\
2 & 0.257 & Filtered & 105 & 7.78 & 4.72 & 4.88 \\
3 & 0.132 & Filtered & 148 & 21.67 & 8.2 & 10.87 \\
4 & & & & &
\end{tabular}

The results showed a significant effect of the degassing treatment as well as the holding of the sand mould under reduced pressure, for a given time before pouring in, on the casting hydrogen content. The average hydrogen content of the samples cut from the solidified undegassed castings (Experiments 1 and 3) and degassed castings (Experiments 2 and 4) were 0.257 and $0.132 \mathrm{~cm}^{3} / 100 \mathrm{~g} \mathrm{Al}$, respectively. The noticeable reduction in the hydrogen level in Experiments 2 and 4 is reasoned to the use of a degassing treatment that was able to decrease the hydrogen content in the melt before pouring, as well as the vacuum treatment of the moulds before the use that seemed to minimise the amount of hydrogen picked by the poured melt from mould walls [39].

Figure 2 shows the Weibull distribution results of the tensile samples. Corresponding plots for the \% elongation are also presented in Figure 3. As shown in the two figures, the data representing both properties are linearly distributed, as suggested by correlation coefficients. In both figures the slope of the data trend lines (that represent the Weibull moduli) of both the UTS and \% elongation in Experiment 4, where degassing and ceramic filters were employed, were the largest among all castings.

By applying the DoE approach to investigate the effect of the process parameters, Figure $4 \mathrm{a}-\mathrm{c}$ shows the effect of hydrogen content, filtration and the interaction between the two parameters, respectively, on mUTS. Corresponding plots related to $\mathrm{m}_{\mathrm{ELONG}}$ are presented in Figure $5 a-c$, respectively. Note that in both Figures $4 \mathrm{~b}$ and $5 \mathrm{~b}$ the points representing the responses are connected using dotted lines, not solid lines, to indicate a categoric factor. 


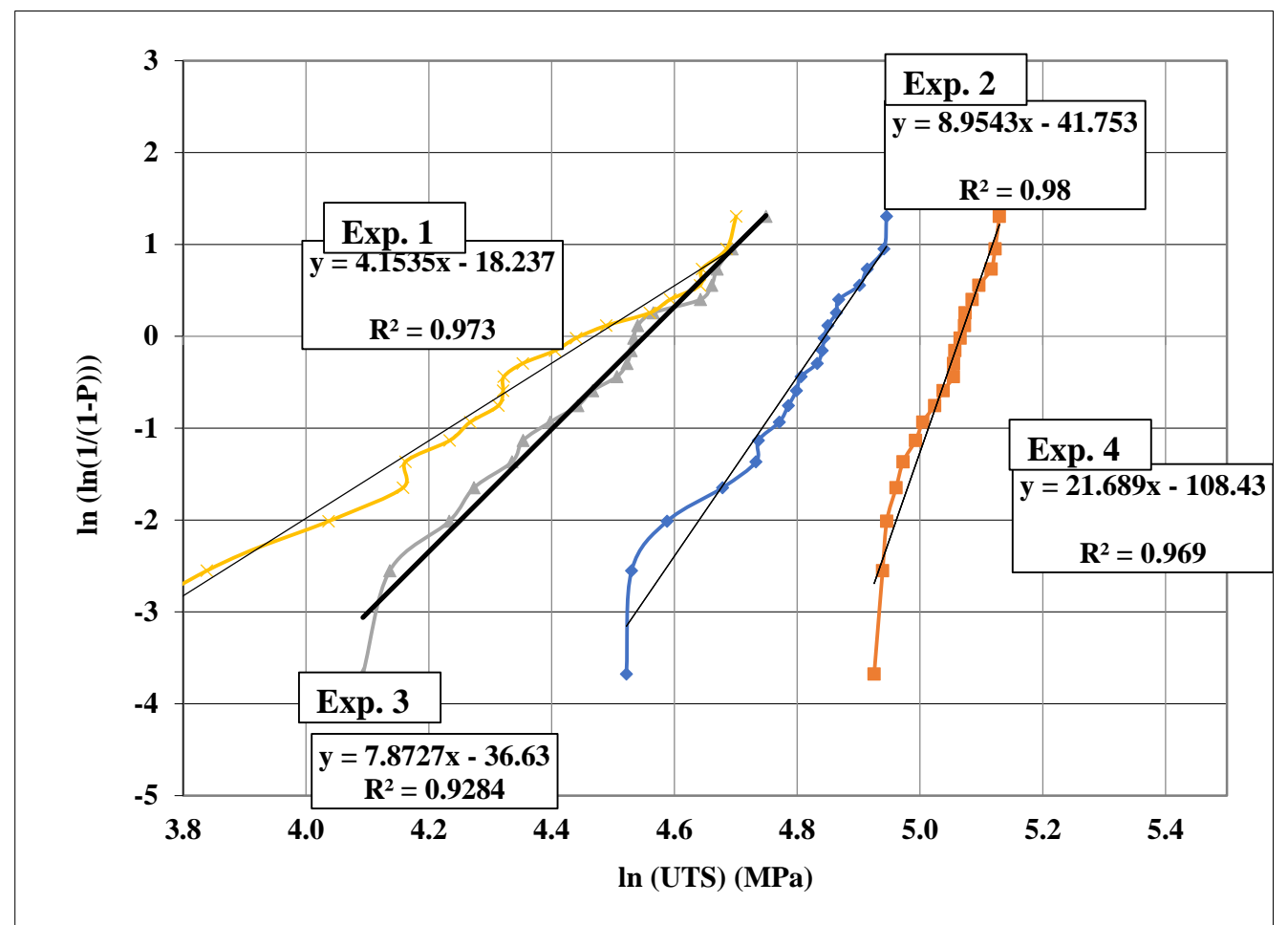

Figure 2. Weibull distribution of UTS of Al-7 Si-0.3 Mg alloy for different experiments itemised in Table 1.

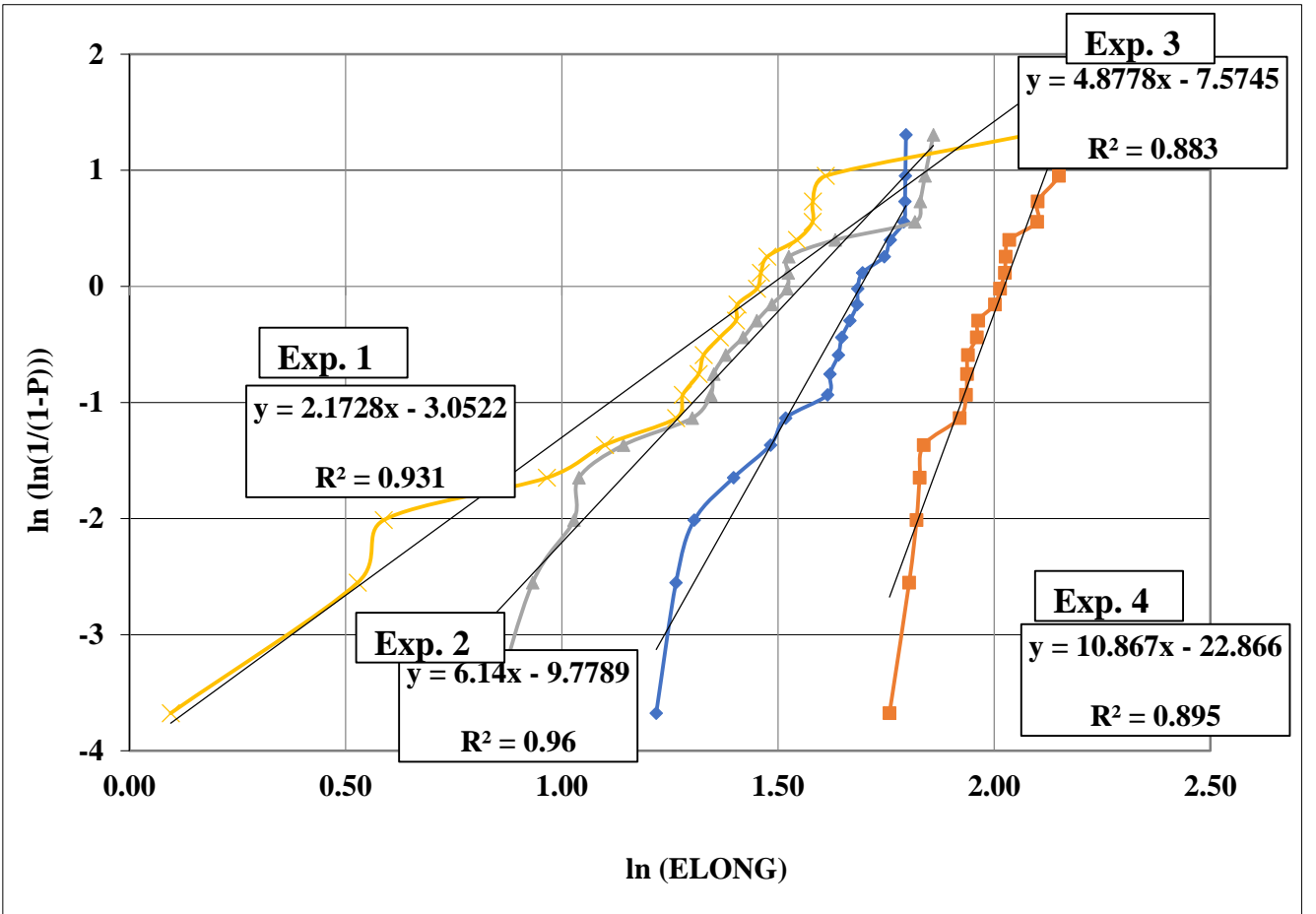

Figure 3. Weibull distribution of \% elongation of $\mathrm{Al}-7 \mathrm{Si}-0.3 \mathrm{Mg}$ alloy for different experiments itemised in Table 1. 
The two figures indicate that both moduli had been increased consistently with either the decrease of hydrogen content and/or the use of filters. The value of mUTS, at a hydrogen level of $0.257 \mathrm{~cm}^{3} / 100 \mathrm{~g} \mathrm{Al}$ and without the use of filters, was about 4 (Experiment 1 ). Decreasing the hydrogen level to $0.132 \mathrm{~cm}^{3} / 100 \mathrm{~g} \mathrm{Al}$ increased the modulus to about 9 , while the use of 10 PPI filters increased the modulus to 8 . However, the application of degassing and mould treatment (that tended to decrease hydrogen level) and the implementation of filters resulted in a significant improvement of mUTS to about 22 (Experiment 4). Moreover, $\mathrm{m}_{\text {ELONG }}$ of about 2 was obtained for the undegassed casting poured in unfiltered moulds.

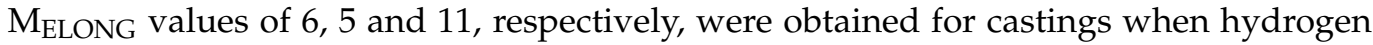
level was reduced, filters were implemented, and both conducts were adopted. Finally, the results suggest that the hydrogen level and filtration interaction is also significant, especially for mUTS, as shown in Figures $4 \mathrm{c}$ and $5 \mathrm{c}$. At lower hydrogen level, the positive effect of filtration on both moduli is clearer. Likewise, the antithesis impact of hydrogen level on the Weibull moduli is more obvious when filtration was adopted.

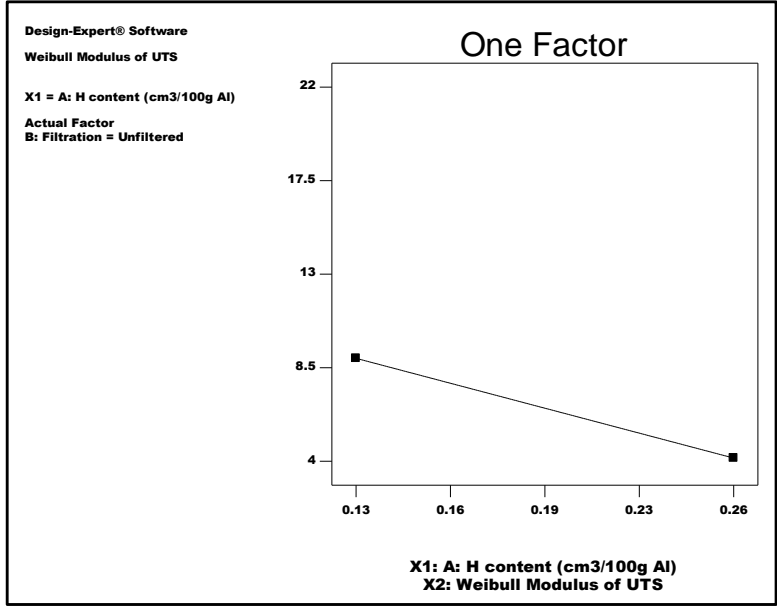

(a)

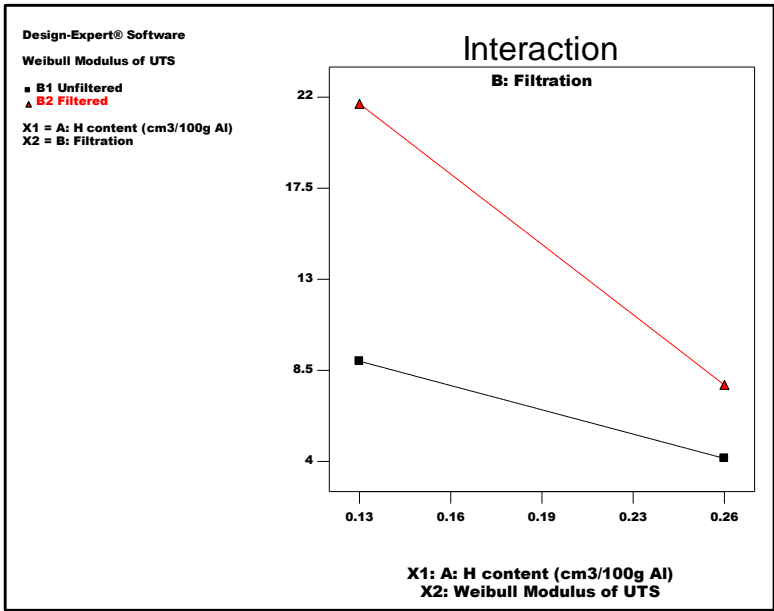

(c)

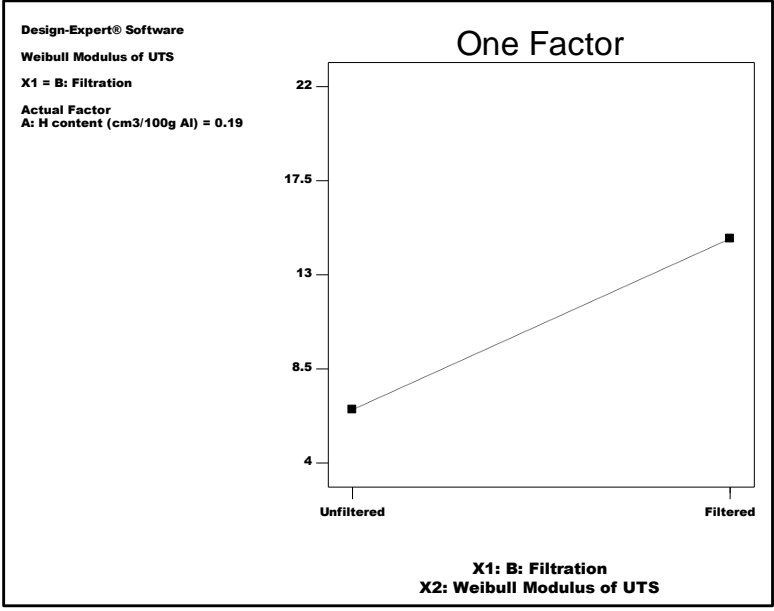

(b)

Figure 4. Effect of (a) hydrogen level, (b) use of filters, (c) the interaction between hydrogen level and filters on muTs. 


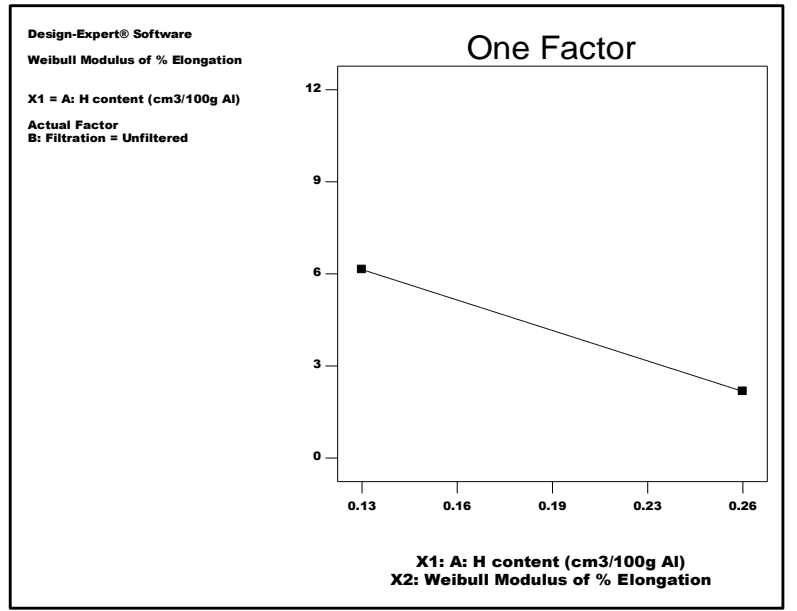

(a)

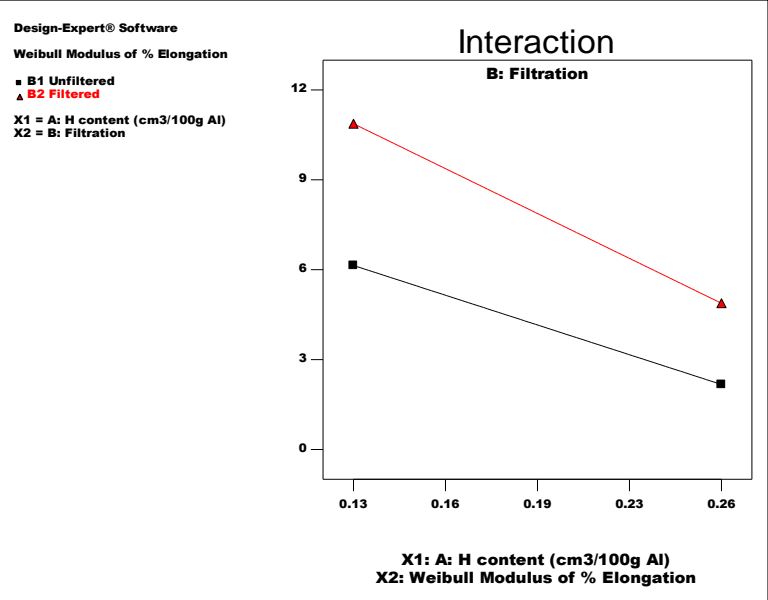

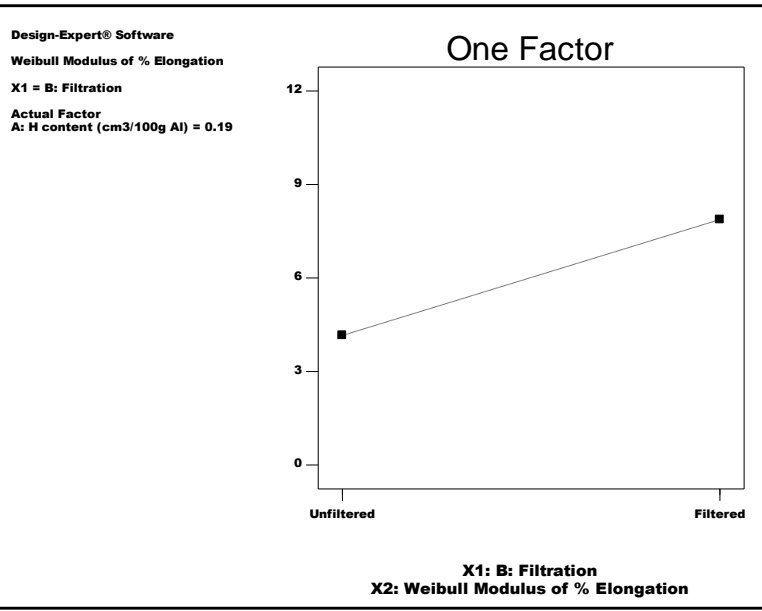

(b)

(c)

Figure 5. Effect of (a) hydrogen level, (b) filtration, (c) the interaction between hydrogen level and filtration on $\mathrm{m}_{\mathrm{ELONG}}$.

The influence of the hydrogen levels, filters, and interaction between them on $\mathrm{x}_{0) \mathrm{UTS}}$

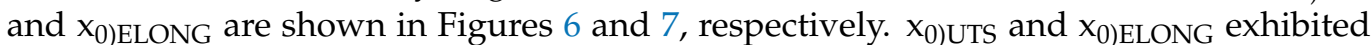

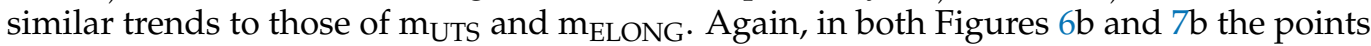
representing the responses are connected using dotted lines, not solid lines, to indicate a categoric factor. The parameters were enhanced 81 to $148 \mathrm{MPa}$ for the UTS, and from 4 to 7 for the \% elongation upon reducing the hydrogen level and use of filters. Furthermore, the interaction between both factors was also revealed to remarkably influence the position parameters of both tensile properties. Employing ceramic filters enabled a sharper rela-

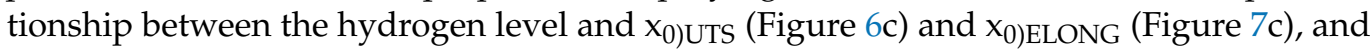
vice versa.

Generally, it was evident that the implementation of ceramic filters and the application of casting procedures that promoted reducing the hydrogen level of the casting had a significant effect on the enhancement of $\mathrm{m}_{\mathrm{UTS}}, \mathrm{x}_{0 \text { )UTS }} \mathrm{m}_{\text {ELONG }}$ and $\mathrm{x}_{0 \text { )ELONG }}$, as could be inferred from Figures 4-7. The Weibull moduli and position parameters were the highest for samples produced in Experiment 4 compared to all castings. This is owed to the use of filters and low hydrogen level castings. This indicates that the casting quality has been improved, and the variability among them has been reduced. 
Literature has demonstrated that the use of a poor gating system, with a runner of $\geq 25 \mathrm{~mm}$ height and without the use of filters, was associated with the formation and entrainment of a substantial amount of bifilm defects [28]. They have also advocated that due to the lack of bonding between the inner (dry) sides of a bifilm, the rejected hydrogen during solidification usually penetrates into the defect and easily expands it, like a balloon, creating a hydrogen pore in the final casting [40]. In Experiment 1, the casting experiment was performed without a prior degassing of the aluminium melt to produce a high hydrogen level casting. This resulted in a substantial drop in the tensile strength of the samples ( $\left.a x_{0}\right)$ UTS of $81 \mathrm{MPa}$ and a $\mathrm{x}_{0}$ )ELONG of $4 \%$ ) and also widened their spread ( 4 and 2, respectively, for mUTS and $\mathrm{m}_{\text {ELONG }}$ ). This could be easily inferred from the results shown in Figures 2-7, as well as in Table 2, which showed that samples from Experiment 1 experienced the worst properties among all experiments.

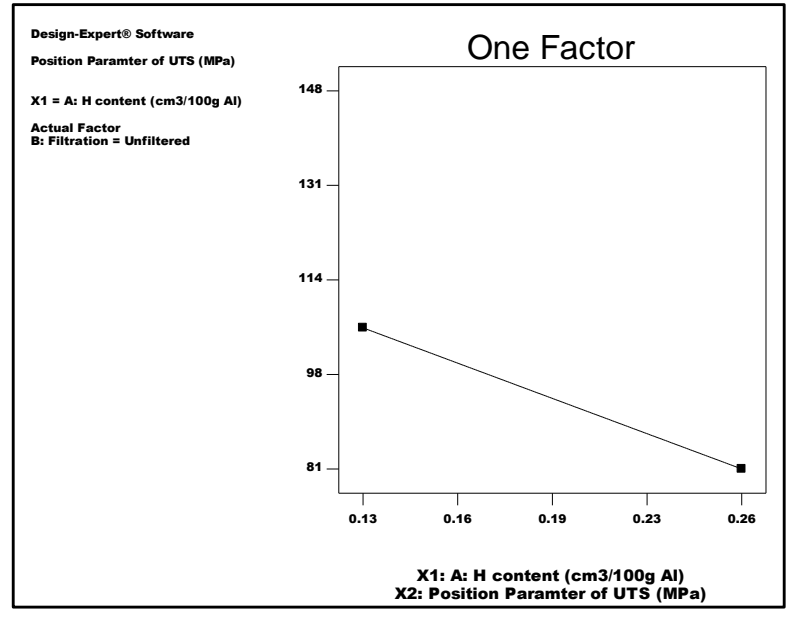

(a)

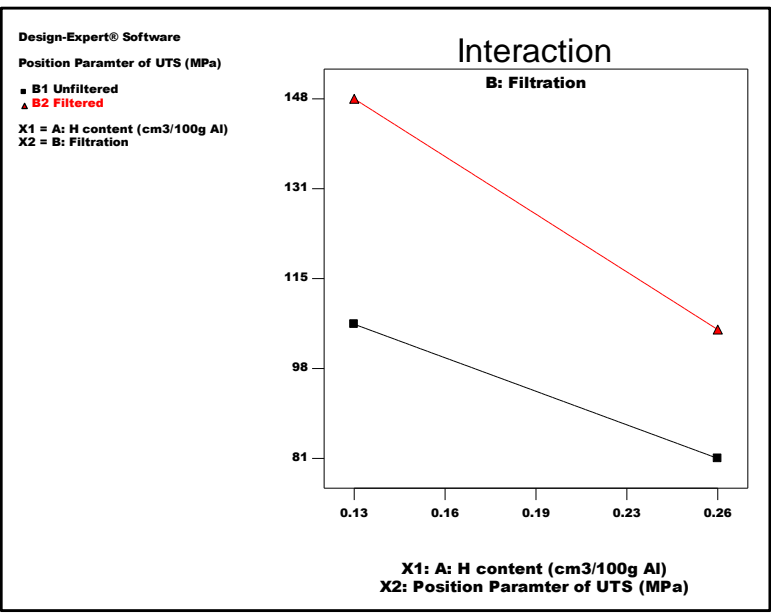

(c)

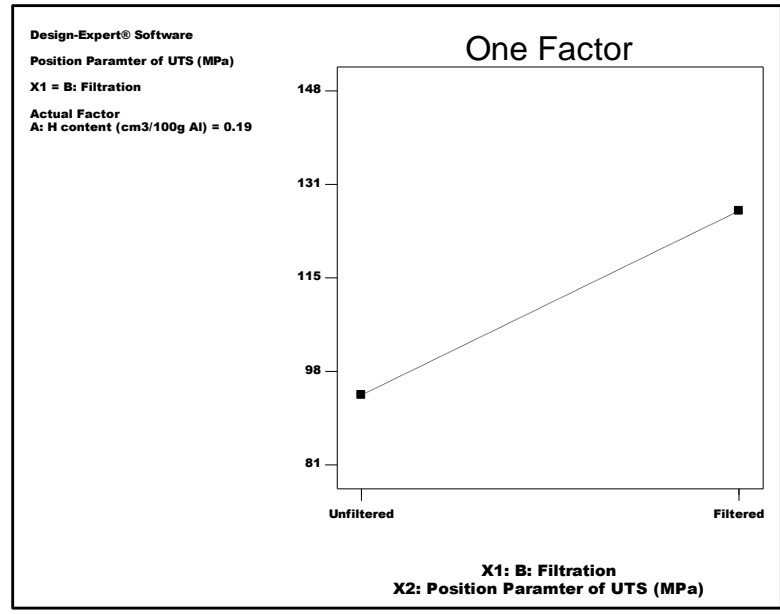

(b)

Figure 6. Influence of (a) hydrogen level, (b) filtration (c) the interaction between hydrogen level and

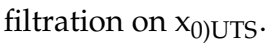




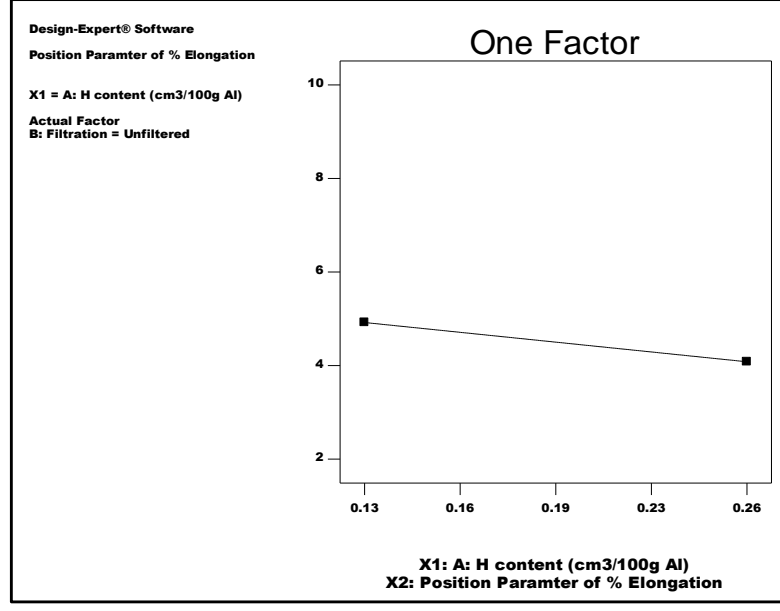

(a)

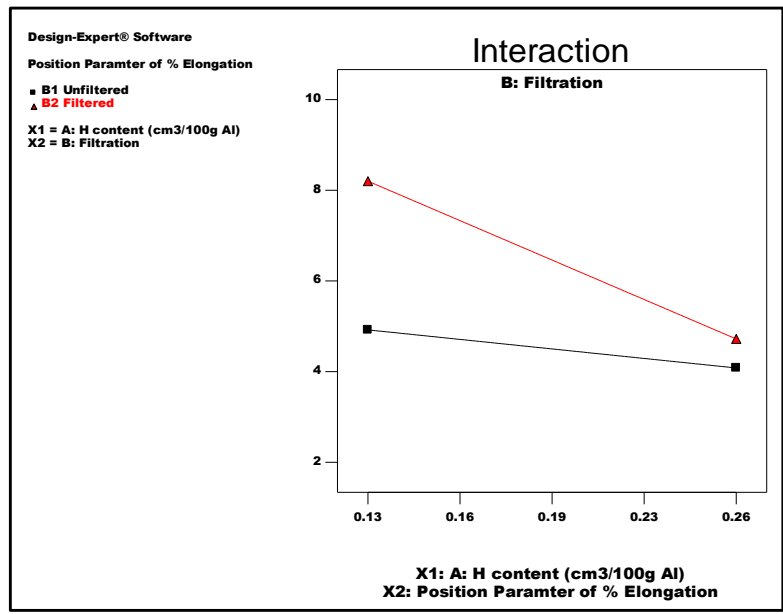

(c)

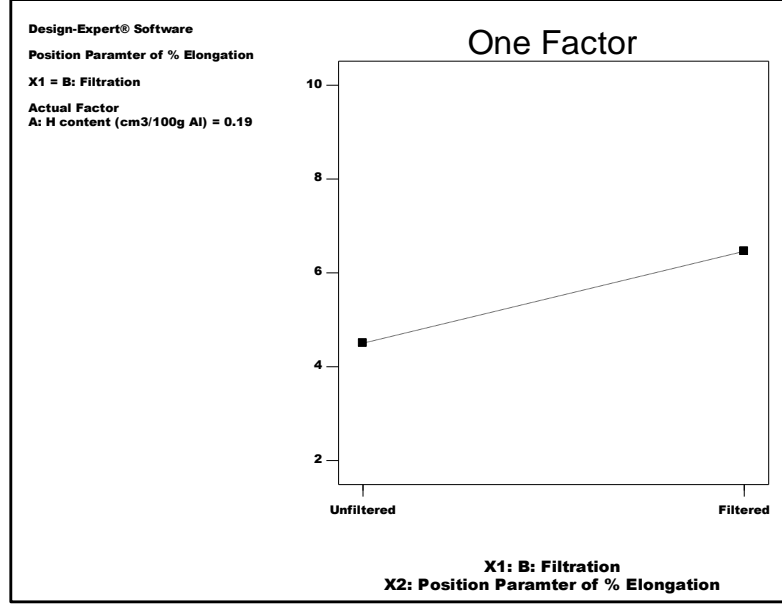

(b)

Figure 7. Graphs of (a) hydrogen level, (b) filtration, (c) the interaction between hydrogen level and filtration against $\mathrm{x}_{0}$ )ELONG.

Using the experimental data, a factorial analysis using Analysis of Variance (ANOVA) statistical approach was executed to determine the standardised effects of studied parameters (the hydrogen level of the casting and filtration) and their interaction on four responses considered in this study: $\mathrm{m}_{\mathrm{UTS}}, \mathrm{x}_{0 \text { )UTS }}, \mathrm{m}_{\mathrm{ELONG}}$ and $\mathrm{x}_{0 \text { )ELONG }}$. Table 3 summarises the list of factors and their interaction, as well as the effect of each factor and/or interaction. The effect is the change in the response as the factor changes from the " -1 " level to the " +1 " level. In other words, the effect of a given factor $\mathrm{A}$ is the difference between the mean values of the response at levels " +1 " and " -1 " of A. A positive value of the effect denotes a lineal influence favouring optimisation, whereas a negative sign signifies a converse repercussion of the parameter on the studied response [41].

It is evident that the $\mathrm{H}$ level of the casting had an adverse effect on $\mathrm{m}_{\mathrm{UTS}}, \mathrm{x}_{0) \mathrm{UTS}}$, $\mathrm{m}_{\text {ELONG }}$ and $\mathrm{x}_{0 \text { )ELONG, }}$, while filtration showed an advantageous effect on the four outputs evaluated in this study, see Table 3. This could be concluded from the signs of the main effects of the two parameters for different responses. However, and independent of the sign of the effect, ANOVA results had demonstrated that the standardised effects of each of the hydrogen levels and filtration on the four responses were too close. This is a clear indication of the important roles played by both factors in influencing the reproducibility of aluminium castings. 
Table 3. Factorial analysis of the properties of the casting.

\begin{tabular}{ccccc}
\hline \multirow{2}{*}{ Term } & \multicolumn{4}{c}{ Standardised Effect } \\
\cline { 2 - 5 } & $\begin{array}{c}\text { Weibull } \\
\text { Modulus of } \\
\text { UTS }\end{array}$ & $\begin{array}{c}\text { Position } \\
\text { Parameter of } \\
\text { UTS (MPa) }\end{array}$ & $\begin{array}{c}\text { Weibull } \\
\text { Modulus of \% } \\
\text { Elongation }\end{array}$ & $\begin{array}{c}\text { Position } \\
\text { Parameter of \% } \\
\text { Elongation (\%) }\end{array}$ \\
\hline A-Hydrogen Level & -9.43 & -34 & -4.98 & -2.16 \\
B-Filtration & 8.18 & 33 & 3.72 & 1.96 \\
AB & -4.56 & -9 & -1.01 & -1.32 \\
\hline
\end{tabular}

The DoE results, presented in Table 3, signified that doubling the hydrogen content was associated with a negative effect on $\mathrm{m}_{\mathrm{UTS}}$ and $\mathrm{x}_{0 \text { )UTS }}$ of about -9 and $-34 \mathrm{MPa}$, respectively, and on $\mathrm{m}_{\mathrm{ELONG}}$ and $\mathrm{x}_{0) \mathrm{ELONG}}$ of about -5 and $-2 \%$, respectively. On the other hand, filtration was shown to have a favourable effect on mUTS $_{\text {UTd }}$ and $\mathrm{x}_{0 \text { )UTS }}$ of about 8 and $33 \mathrm{MPa}$, respectively, and on $\mathrm{m}_{\mathrm{ELONG}}$ and $\mathrm{x}_{0 \text { )ELONG }}$ of about 4 and $2 \%$, respectively. This might be due to the role played by the filters in damping the acceleration of the incoming flow of liquid $\mathrm{Al}$ during its passage through the runner. This would permit a calmer and smoother flow behaviour of the melt inside the mould, reduce the ingate velocity, minimise oxide film entrainment, and ultimately improve the tensile properties. This confirms the results obtained by Green and Campbell [38,42], who apprised a considerable improvement in the Weibull moduli of the tensile properties of Al-7Si-Mg castings, of about $350 \%$, while applying a turbulent-free filling system that seemed to prevent oxide film entrainment.

Bifilm defects were detected at the specimens' fracture surfaces from the four experiments carried out in this work. Typical examples of such defects from Experiments 1 and 4 are shown in Figures 8 and 9, respectively. Results of the accompanied EDX examination at the suspected oxide films confirmed that spinel films existed at these surfaces. The EDX spectra contained a peak for carbon which was suggested to be caused by the contamination of the atmosphere inside the SEM. The identity of the spinel films was confirmed by EDX analyses that detected relatively large amounts of oxygen at the suspected oxide films (indicated by the high oxygen peak in the EDX spectrum), which had not been detected in other adjacent areas of the fracture surface being examined. It was shown that the approximate average areas of the spinel layers detected on the fracture surfaces of the examined test bars (assuming an elliptical shape for the oxide film) from Experiments 1 and 4 were about 1.4 and $4.5 \mathrm{~mm}^{2}$, respectively.

In Experiment 1 the bad mould design and the lack of filtration are expected to violate the critical ingate velocity and accordingly plenteous entrainment of oxide films is expected. Additionally, the relatively high hydrogen level of the castings in this experiment (about $0.257 \mathrm{~cm}^{3} / 100 \mathrm{~g} \mathrm{Al}$ ) was expected to increase the hydrogen ingress into the bifilms and increase their sizes. Therefore, several oxide film defects of comparatively larger sizes were often detected at the fracture surfaces of test bars from this experiment. See Figure 8. In contrast, the area covered with oxide layers detected on the fracture surface of a specimen from Experiment 4 (Figure 9) was considerably smaller than that in the casting from Experiment 1 by about one-third. This is suggested to be a result of the significantly lower hydrogen level of the former experiment due to the application of degassing, as well as the use of filters that seemed to minimise the oxide film entrainment during mould filling.

The substantial reduction in the amount and size of bifilm defects, which is related to the combined effect of the two casting parameters, caused the castings from Experiment 4 to have a noticeable improvement of their $\mathrm{m}_{\mathrm{UTS}}$ and $\mathrm{m}_{\mathrm{ELONG}}$ by about $420 \%$ and $400 \%$, respectively, compared to those in Experiment 1. Moreover, a less significant increase in $\mathrm{x}_{0) \mathrm{UTS}}$ and $\mathrm{x}_{0 \text { )ELONG }}$ of about $82 \%$ and $101 \%$ respectively was obtained due to the reduced hydrogen level and the use of filters. See Table 2. 
The connotation of the current findings would be that the implementation of filters could significantly reduce the production of bifilm defects. Moreover, the reduction of casting hydrogen level would minimise the amount of the gas diffuses into the entrained bifilms, decreasing the size of the defects. Thus, if appropriate treatment procedures for both the melt and the sand mould would be considered, this would permit the production of castings with minimum hydrogen level. Additionally, if filtration was applied, this would allow a more quiescent mould filling regime. These considerations would allow a casting producer to reduce both the number and the size of the bifilms in the melt and consequently obtaining an Al cast alloy with improved mechanical properties.

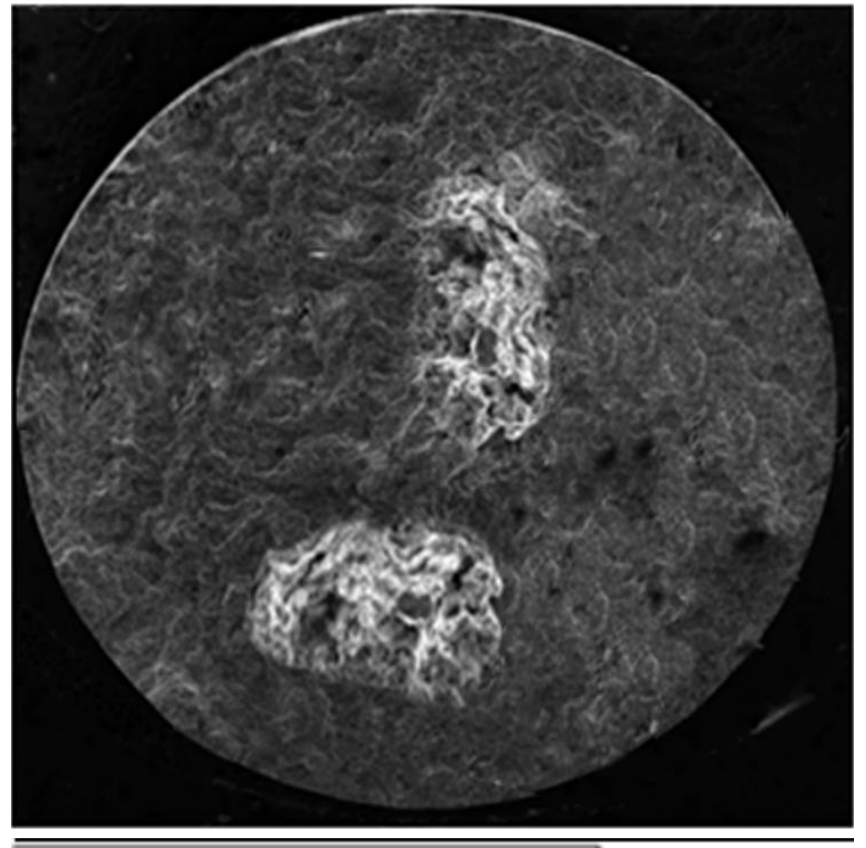

$5 \mathrm{~mm}$

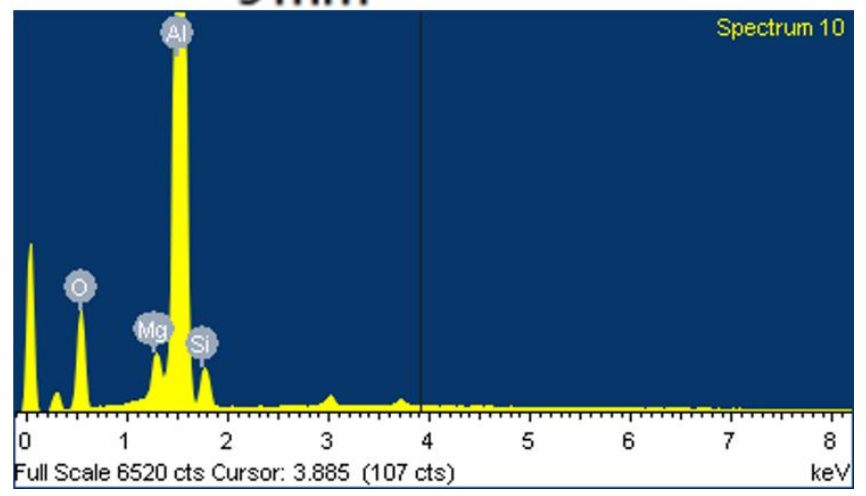

(a)

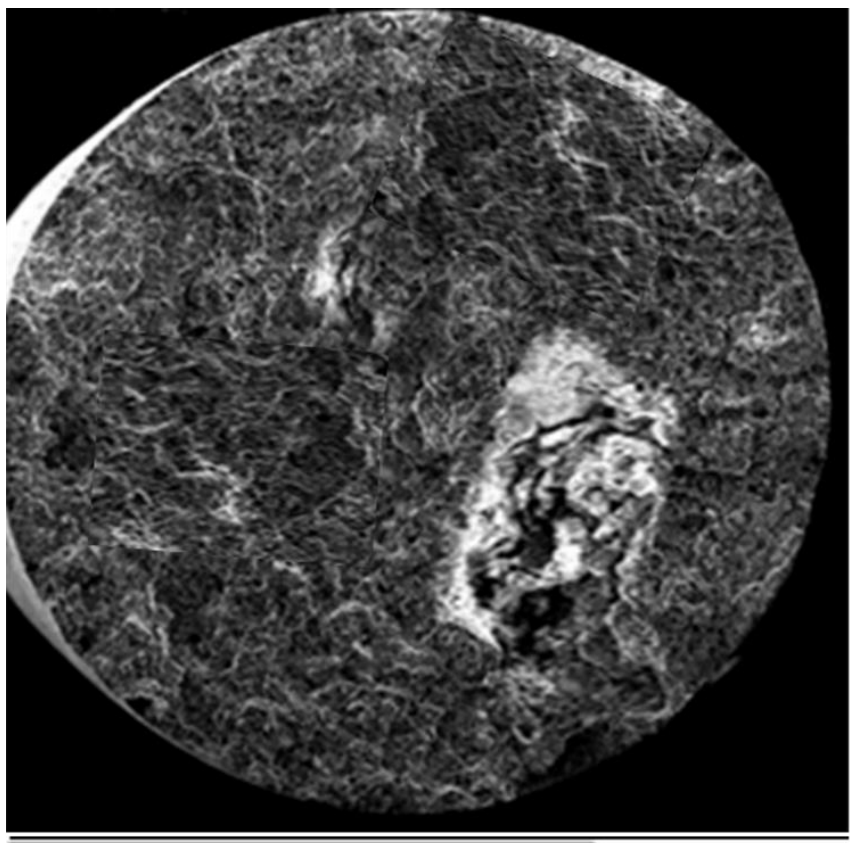

$5 \mathrm{~mm}$

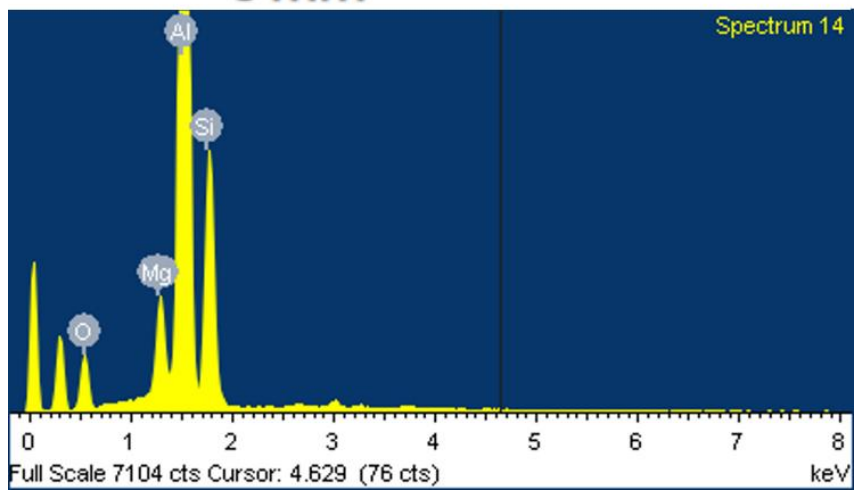

(b)

Figure 8. $(\mathbf{a}, \mathbf{b})$ Electron microscopy fractographs and corresponding EDX spectra (at the positions pointed with " $\mathrm{X}$ ") of oxide films on the fracture surfaces of two tensile-tested bars from Experiment 1. 


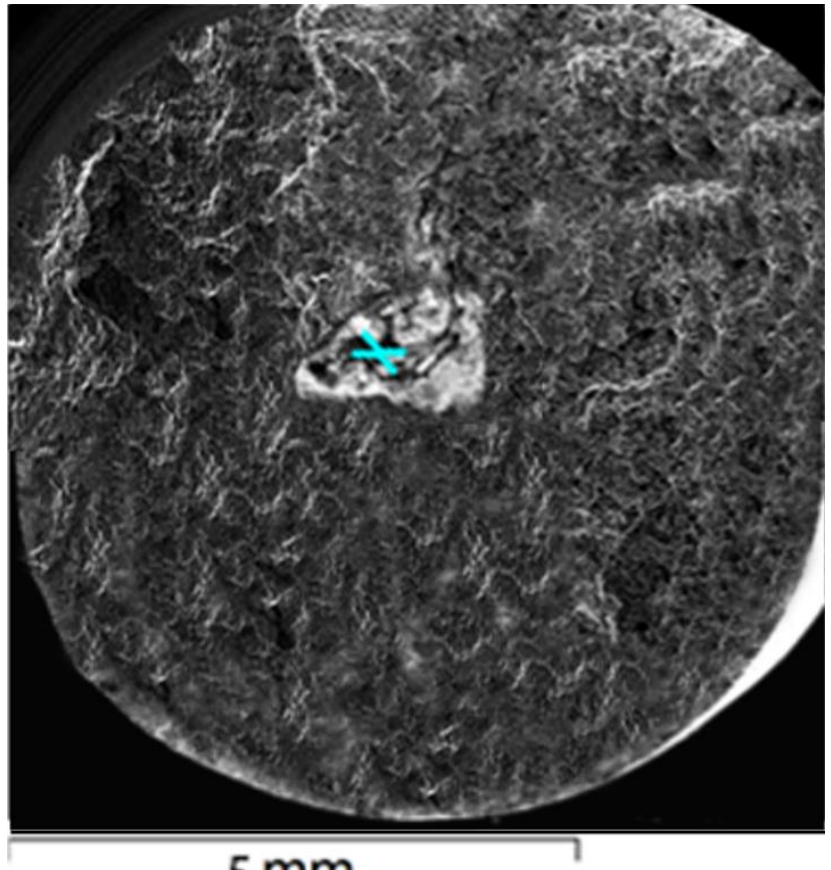

$5 \mathrm{~mm}$

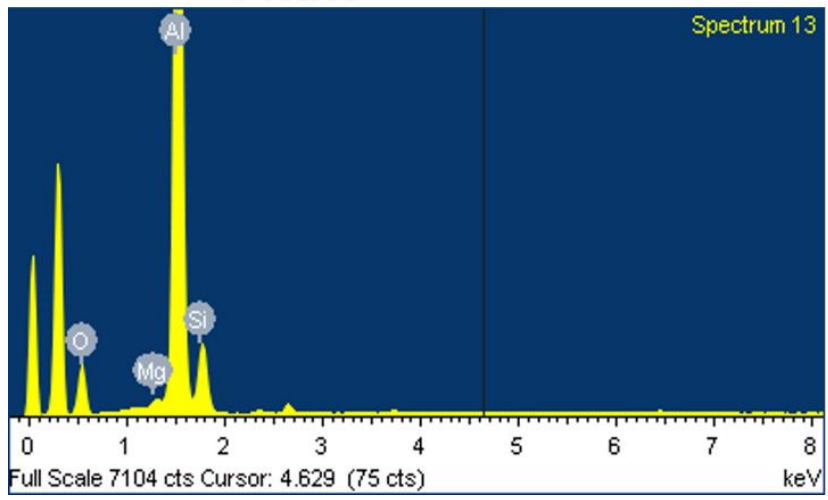

(a)

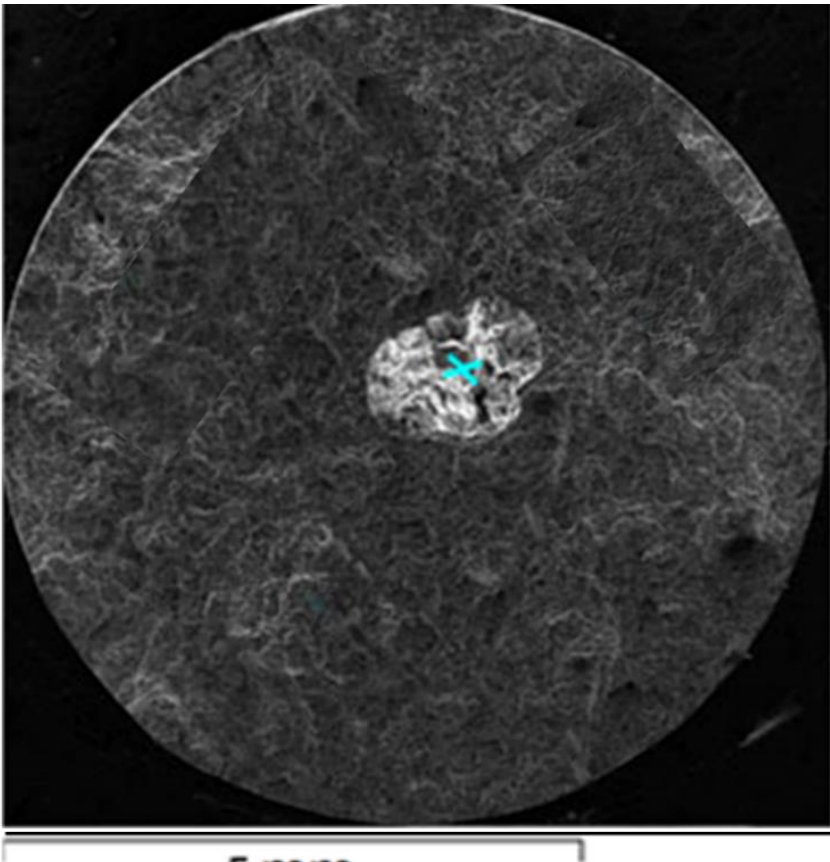

$5 \mathrm{~mm}$

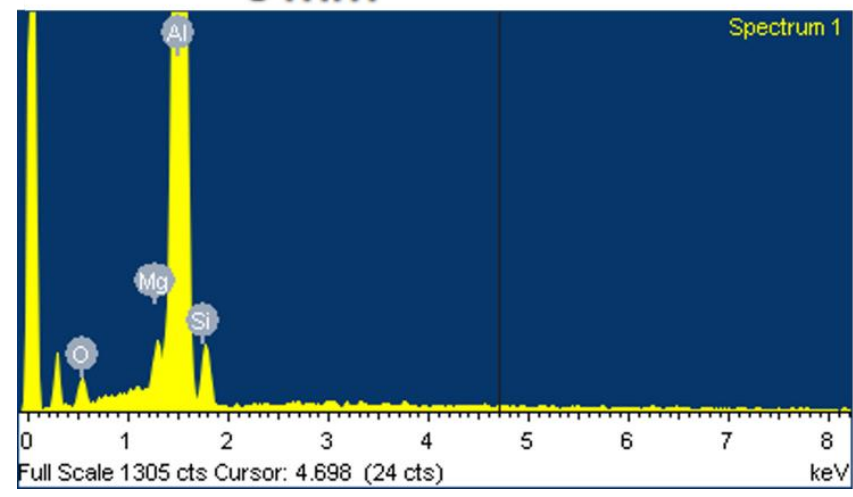

(b)

Figure 9. $(\mathbf{a}, \mathbf{b})$ Electron microscopy fractographs and corresponding EDX spectra (at the positions pointed with " $\mathrm{X}$ ") of oxide films on the fracture surfaces of two tensile-tested bars from Experiment 4.

\section{Conclusions}

1. The detection of bifilms at fracture surfaces of the majority of tensile samples examined is a suggestion of the deleterious influence of these inclusions on the mechanical properties of $\mathrm{Al}$ cast alloys.

2. ANOVA results suggested that reducing the hydrogen content of an Al-7 Si-0.3 Mg cast alloy and the application of 10 PPI filters had remarkable positive standardised effects of about 9 and 4, respectively, on the UTS and \% elongation Weibull modulus.

3. Statistical analysis also indicated that both parameters had significant standardised effects on the UTS and \% elongation position parameters, of $33 \mathrm{MPa}$ and $2 \%$, respectively.

4. The optimised casting condition involving the implementation of filters and the application of the precautions required to decrease the hydrogen level of the casting resulted in an outstanding improvement of the Weibull moduli of the UTS and \% elongation by a factor of about 4 .

Author Contributions: Conceptualization, M.A.E.-S., K.E. and H.H.; methodology, M.A.E.-S., K.E. and H.H.; software, M.A.E.-S., K.E. and H.H.; writing-original draft preparation, M.A.E.-S., K.E. and H.H.; writing-review and editing, M.A.E.-S., K.E. and H.H. All authors have read and agreed to the published version of the manuscript. 
Funding: This research received no external funding.

Institutional Review Board Statement: Not applicable.

Informed Consent Statement: Not applicable.

Data Availability Statement: The data presented in this study are available on request from the corresponding author.

Conflicts of Interest: The authors declare no conflict of interest.

\section{References}

1. Divandari, M.; Campbell, J. A new technique for the study of aluminum oxide films. Aluminum Trans. 2000, 2, $233-238$.

2. Dai, X.; Yang, X.; Campbell, J.; Wood, J. Influence of oxide film defects generated in filling on mechanical strength of aluminium alloy castings. Mater. Sci. Technol. 2004, 20, 505-513. [CrossRef]

3. Divandari, M.; Campbell, J. Oxide film characteristics of Al-7Si-Mg alloy in dynamic conditions in casting. Int. J. Cast Met. Res. 2004, 17, 182-187. [CrossRef]

4. Wang, Q.; Crepeau, P.; Davidson, C.; Griffiths, J. Oxide films, pores and the fatigue lives of cast aluminum alloys. Metall. Mater. Trans. B 2006, 37, 887-895. [CrossRef]

5. Mirak, A.; Divandari, M.; Boutorabi, S.; Campbell, J. Oxide film characteristics of AZ91 magnesium alloy in casting conditions. Int. J. Cast Met. Res. 2007, 20, 215-220. [CrossRef]

6. Campbell, J. Entrainment defects. Mater. Sci. Technol. 2006, 22, 127-145. [CrossRef]

7. Erzi, E.; Gürsoy, Ö.; Yüksel, Ç.; Colak, M.; Dispinar, D. Determination of Acceptable Quality Limit for Casting of A356 Aluminium Alloy: Supplier's Quality Index (SQI). Metals 2019, 9, 957. [CrossRef]

8. Matejka, M.; Bolibruchová, D.; Podprocká, R. The Influence of Returnable Material on Internal Homogeneity of the High-Pressure Die-Cast $\mathrm{AlSi}_{9} \mathrm{Cu}_{3}(\mathrm{Fe})$ Alloy. Metals 2021, 11, 1084. [CrossRef]

9. Neuser, M.; Grydin, O.; Andreiev, A.; Schaper, M. Effect of Solidification Rates at Sand Casting on the Mechanical Joinability of a Cast Aluminium Alloy. Metals 2021, 11, 1304. [CrossRef]

10. Souissi, N.; Souissi, S.; Niniven, C.L.; Amar, M.B.; Bradai, C.; Elhalouani, F. Optimization of Squeeze Casting Parameters for 2017 A Wrought Al Alloy Using Taguchi Method. Metals 2014, 4, 141-154. [CrossRef]

11. Griffiths, W.; Lai, N.-W. Double oxide film defects in cast magnesium alloy. Metall. Mater. Trans. A 2007, 38, 190-196. [CrossRef]

12. Raiszadeh, R.; Griffiths, W. The behaviour of double oxide film defects in liquid Al alloys under atmospheric and reduced pressures. J. Alloys Compd. 2010, 491, 575-580. [CrossRef]

13. El-Sayed, M.A. The behaviour of bifilm defects in cast Al-7Si-Mg alloy. PLoS ONE 2016, 11, e0160633. [CrossRef]

14. El-Sayed, M.; Salem, H.G.; Kandeil, A.-R.; Griffiths, W.D. A study of the behaviour of double oxide films in Al alloy melts. In Materials Science Forum; Trans Tech Publications Ltd.: Zurich, Switzerland, 2013; pp. 260-265.

15. Hamed Basuny, F.; Ghazy, M.; Kandeil, A.-R.; El-Sayed, M.A. Effect of casting conditions on the fracture strength of Al-5 Mg alloy castings. Adv. Mater. Sci. Eng. 2016. [CrossRef]

16. Lai, N.; Griffiths, W.; Campbell, J. Modelling of the potential for oxide film entrainment in light metal alloy castings. Modeling Cast. Weld. Adv. Solidif. Processes-X 2003, 415-422. Available online: https://www.researchgate.net/profile/John-Campbell38/publication/260629687_Modelling_of_the_potential_for_oxide_film_entrainment_in_light_metal_alloy_castings/links/02 e7e5349543c16b2a000000/Modelling-of-the-potential-for-oxide-film-entrainment-in-light-metal-alloy-castings (accessed on 3 December 2021).

17. Raiszadeh, R.; Griffiths, W. The effect of holding liquid aluminum alloys on oxide film content. Metall. Mater. Trans. B 2011, 42 , 133-143. [CrossRef]

18. Reilly, C.; Green, N.; Jolly, M.; Gebelin, J.-C. The modelling of oxide film entrainment in casting systems using computational modelling. Appl. Math. Modell. 2013, 37, 8451-8466. [CrossRef]

19. Campbell, J. Castings; Elsevier: Amsterdam, The Netherlands, 2003.

20. El-Sayed, M.A.M. Double Oxide Film Defects and Mechanical Properties in Aluminium Alloys; University of Birmingham: Birmingham, UK, 2012.

21. Griffiths, W.; Caden, A.; El-Sayed, M. The Behaviour of Entrainment Defects in Aluminium Alloy Castings. In Proceedings of the 2013 International Symposium on Liquid Metal Processing and Casting, Austin, TX, USA, 22-25 September 2013 ; pp. 187-192.

22. Griffiths, W.D.; Caden, A.; El-Sayed, M. An investigation into double oxide film defects in aluminium alloys. In Materials Science Forum; Trans Tech Publications Ltd.: Zurich, Switzerland, 2014; pp. 142-147.

23. Bahreinian, F.; Boutorabi, S.M.A.; Campbell, J. Critical gate velocity for magnesium casting alloy (ZK51A). Int. J. Cast Met. Res. 2006, 19, 45-51. [CrossRef]

24. Cox, M.; Wickins, M.; Kuang, J.P.; Harding, R.A.; Campbell, J. Effect of top and bottom filling on reliability of investment castings in $\mathrm{Al}, \mathrm{Fe}$, and Ni based alloys. Mater. Sci. Technol. 2000, 16, 1445-1452. [CrossRef]

25. Halvaee, A.; Campbell, J. Critical mold entry velocity for aluminum bronze castings. AFS Trans. 1997, 105, 35-46.

26. Runyoro, J.; Boutorabi, S.M.A.; Campbell, J. Critical gate velocities for film-forming casting alloys: A basic for process specification. AFS Trans. 1992, 100, 225-234. 
27. Dispinar, D.; Campbell, J. Critical assessment of reduced pressure test. Part 1: Porosity phenomena. Int. J. Cast Met. Res. 2004, 17, 280-286. [CrossRef]

28. El-Sayed, M.; Griffiths, W. Hydrogen, bifilms and mechanical properties of Al castings. Int. J. Cast Met. Res. 2014, 27, 282-287. [CrossRef]

29. El-Sayed, M.; Hassanin, H.; Essa, K. Effect of casting practice on the reliability of Al cast alloys. Int. J. Cast Met. Res. 2016, 29, 350-354. [CrossRef]

30. Chen, Q.; Griffiths, W. The investigation of the floatation of double oxide film defect in liquid aluminium alloys by a four-point bend test. Int. J. Cast Met. Res. 2019, 32, 221-228. [CrossRef]

31. Chen, Q.; Griffiths, W. Modification of Double Oxide Film Defects with the Addition of Mo to An Al-Si-Mg Alloy. Metall. Mater. Trans. B. 2021, 52, 502-516. [CrossRef]

32. Laakso, P.; Riipinen, T.; Laukkanen, A.; Andersson, T.; Jokinen, A.; Revuelta, A.; Ruusuvuori, K. Optimization and simulation of SLM process for high density H13 tool steel parts. Phys. Procedia 2016, 83, 26-35.

33. Leary, M.; Mazur, M.; Elambasseril, J.; McMillan, M.; Chirent, T.; Sun, Y.; Qian, M.; Easton, M.; Brandt, M. Selective laser melting (SLM) of AlSi12Mg lattice structures. Mater. Des. 2016, 98, 344-357. [CrossRef]

34. Pawlak, A.; Rosienkiewicz, M.; Chlebus, E. Design of experiments approach in AZ31 powder selective laser melting process optimization. Arch. Civ. Mech. Eng. 2017, 17, 9-18. [CrossRef]

35. El-Sayed, M.A.; Essa, K.; Ghazy, M.; Hassanin, H. Design optimization of additively manufactured titanium lattice structures for biomedical implants. Int. J. Adv. Manuf. Technol. 2020, 110,1-12. [CrossRef]

36. Croarkin, C.; Tobias, P.; Zey, C. Engineering Statistics Handbook; The Institute Gaithersburg: Gaithersburg, MD, USA, 2001.

37. Weibull, W. A statistical distribution function of wide applicability. J. Appl. Mech. 1951, 18, 293-297. [CrossRef]

38. Green, N.R.; Campbell, J. Statistical distributions of fracture strengths of cast Al-7Si-Mg alloy. Mater. Sci. Eng. A 1993, 173, 261-266. [CrossRef]

39. Winardi, L.; Griffin, R.D.; Littleton, H.E.; Griffin, J.A. Variables Affecting Gas Evolution Rates and Volumes from Cores in Contact with Molten Metal. AFS Trans. 2008, 116, 505.

40. Farhoodi, B.; Raiszadeh, R.; Ghanaatian, M.-H. Role of double oxide film defects in the formation of gas porosity in commercial purity and Sr-containing Al alloys. J. Mater. Sci. Technol. 2014, 30, 154-162. [CrossRef]

41. Nayak, A.K.; Pal, D.; Santra, K. Ispaghula mucilage-gellan mucoadhesive beads of metformin HCl: Development by response surface methodology. Carbohydr. Polym. 2014, 107, 41-50. [CrossRef] [PubMed]

42. Green, N.; Campbell, J. Influence of oxide film filling defects on the strength of Al-7Si-Mg alloy castings. AFS Trans. 1994, 102, 341-347. 